\title{
Quantitative immunohistochemical analyses of the expression of E-cadherin, thrombomodulin, CD44H and CD44v6 in primary tumours of pharynx/larynx squamous cell carcinoma and their lymph node metastases
}

Rocío Hernández Gaspar a , Juan R. de los Toyos a , César Álvarez Marcos ${ }^{b}$, José Ramón Riera ${ }^{\mathrm{c}}$ and Andrés Sampedro ${ }^{\mathrm{a}, *}$

a Servicio de Proceso de Imágenes y Citometría, Universidad de Oviedo, Oviedo, Asturias

${ }^{\mathrm{b}}$ Servicio de Otorrinolaringología, Hospital Valle del Nalón, Langreo, Asturias

${ }^{\mathrm{c}}$ Servicio de Anatomía Patológica, Hospital Valle del

Nalón, Langreo, Asturias

Received 3 December 1998

Accepted 2 July 1999

The quantitative expression of E-cadherin, thrombomodulin, $\mathrm{CD} 44 \mathrm{H}$ and CD44v6 in 32 specimens of primary tumours of pharynx/larynx squamous cell carcinoma and their lymph node metastases was studied by immunohistochemistry. With the aim of obtaining comparative and objective data, image acquisition conditions were kept unaltered for all the measurements and the immunostaining intensity was quantified by applying an image processing system. On the one hand, correlations were only observed between CD44H and CD44v6, both in primary tumours and metastases, and between E-cadherin and TM in metastases. On the other hand, statistical analyses of paired data did not show significant differences in the expression of these markers between the two tumour sites. In agreement with previous reports, E-cadherin

\footnotetext{
${ }^{*}$ Correspondence to: Andrés Sampedro, Servicio de Proceso de Imágenes y Citometría, Universidad de Oviedo, Hospital Central de Asturias, Bloque Polivalente A, planta $1^{\mathrm{a}}$, c/ Julián Clavería $\mathrm{s} / \mathrm{n}$, 33006 Oviedo, Spain. Tel.: +34 9851036 60; Fax: +34 9851036 58; E-mail: andres@spi.uniovi.es.
}

expression was rather low or negative in primary tumours and metastases of the three poorly differentiated specimens we studied, as well as that of TM, but otherwise some of these samples showed intermediate immunostaining levels of CD44H/CD44v6. It may be concluded from the present study that the quantitative expression of these adhesion molecules in well established lymph node metastases of pharynx/larynx squamous cell carcinoma is essentially unaltered in relation to their primary sites.

Keywords: Immunohistochemistry, adhesion molecules, pharynx/larynx squamous cell carcinoma, lymph node metastases

\section{Introduction}

Tumour invasion and metastasis comprise a cascade of events, among which cell-cell and cell-matrix interactions play a crucial role [1]. The expression of several cell-cell and cell-matrix adhesion molecules has been associated with the invasive and metastatic potential of squamous cell carcinoma (SCC).

E-cadherin mediates homophylic interactions between epithelial cells and is necessary for the maintenance of the epithelial architecture [4]. Thrombomodulin (TM) has been shown to be expressed in the squamous epithelium and squamous malignancies of different body locations, mainly at the intercellular bridges [12,14,27]. CD44 isoforms, comprising several exon variants expressed according to a limited number of combinations, mediate cell-cell and cell-matrix attachment in different tissues. The v6 splice variant has 
been putatively involved in the vascular dissemination and homing of tumoural cells $[8,21,29]$.

Prognosis and treatment of patients with head and neck squamous cell carcinoma (HNSCC) are dependent on the status of regional lymph nodes [10, 22]. Therefore, the accurate characterization of the metastatic phenotype of this tumour is of great importance. There have been rather conflicting reports regarding the correlation between E-cadherin and CD44v6 (v6 splice variant-containing isoforms of CD44) expression and lymph node involvement in HNSCC [2,3,9,11,13,15,18,19,23-25]. TM downexpression has also been associated with metastasis of esophageal and oral carcinoma cells [26,28].

All these results refer to immunohistochemical analyses in which immunostaining intensity and/or percentages of positive cells were subjectively evaluated and so this methodology leads to rather inaccurate scorings. We have therefore quantified the immunohistochemical expression of E-cadherin, TM, CD44H (standard isoform of CD44) and CD44v6 in 32 cases of SCC of pharynx/larynx, applying an image processing system. Comparative measurements between primary tumours and their corresponding lymph node metastases were made. The phenotype of these metastases in relation to the four adhesion molecules has been characterized.

\section{Materials and methods}

\subsection{Tissue specimens}

Surgical samples were obtained from 32 male patients with primary SCC of pharynx/larynx, who presented lymph node metastases at the moment of surgical intervention in the Hospital Valle del Nalón. Samples of normal pharynx/larynx epithelium, adjacent to tumour sites, and primary tumour and lymph node metastases were collected between 1992 and 1996, taken from surgical resection specimens. Table 1 shows the characteristics of these samples, with reference to patient age, tumour site, type of surgery, histological differentiation grade, lymph node involvement and exitus. Most of the samples (78\%) corresponded to moderately differentiated tumours. Tissue specimens were fixed in formalin and embedded in paraffin.

\subsection{Antibodies}

Primary antibodies were: anti-E-cadherin (clone 36; Transduction Laboratories, Lexington, KY, USA), anti-TM (clone 1009; Dako A/S, Glostrup, Denmark), anti-CD44H (clone 2C5; R\&D Systems, Oxon, UK) and anti-CD44v6 (clone 2F10; R\&D Systems).

\subsection{Immunostaining procedures}

The paraffin blocks were cut into 3- $\mu$ m thick tissue sections and deparaffined with xylene. They were then heated for $3 \mathrm{~min}$ in a pressure cooker or for $7 \mathrm{~min}$ in a microwave oven for E-cadherin and CD44 epitope retrieval, respectively; this pretreatment was not used for TM immunostaining. After endogenous peroxidase inactivation and blocking with nonfat dry milk, tissue sections were incubated with the primary antibodies, according to the following scheme: anti E-cadherin, at 1 : 100 overnight; anti-TM at $1: 10$ for 1 hour; and anti-CD44H and anti-CD44v6, at $1: 1000$ for 1 hour. The ABC-Alkaline Phosphatase Method (Vector Laboratories, Burlingame, CA, USA) was then applied to the anti-E-cadherin antibody; and the ABCPeroxidase Method (Vector Laboratories) to the antiTM, anti-CD44H and anti-CD44v6 antibodies. Fast Red and 3,3-diaminobenzidine were used as chromogenic substrates for alkaline phosphatase and peroxidase, respectively. Finally, the sections were rinsed with tap water, counterstained with hematoxylin, and mounted.

\subsection{Immunohistochemical quantitation}

Images were recorded with the aid of a JVC color video camera, TK 870E model (JVC España, S.A., Barcelona, Spain), through a DPLAN $20 \times 0.40$ NA objective lens attached to an Olympus BHSP microscope (Olympus Optical Co., Tokyo, Japan); no specific filters were set at this step.

The intensity of the immunostaining was quantified by image processing with the MIP program (Microm España, S.A., Barcelona, Spain) by means of the IMCO 10 image analyzer (Kontron Elektronik GmbH, Eching, Germany). To avoid affecting the immunostaining intensity by external causes, image acquisition conditions were kept unaltered for all the measurements. A relative immunostaining scale was set for each marker, after discrimination of stained and nonstained pixels based on the estimated red, green and blue band ranges (between 0 and 255). Five different 
Table 1

Tumour characteristics

\begin{tabular}{|c|c|c|c|c|c|c|}
\hline $\begin{array}{l}\text { Case } \\
\text { no. }\end{array}$ & $\begin{array}{l}\text { Patient } \\
\text { age }\end{array}$ & Tumour site ${ }^{\mathrm{a}}$ & $\begin{array}{l}\text { Type of } \\
\text { surgery }\end{array}$ & $\begin{array}{c}\text { Histologic grade of } \\
\text { differentiation }\end{array}$ & $\begin{array}{l}\text { Cervical lymph nodes } \\
\text { metastatized/studied }\end{array}$ & Exitus \\
\hline 1 & 63 & $\begin{array}{l}\text { Vallecula } \mathrm{R}-\mathrm{L}+\text { base } \\
\text { of the tongue }\end{array}$ & $\mathrm{SL}$ & poor & $6 / 43$ & + \\
\hline 2 & 59 & $\begin{array}{l}\text { Laryngeal surface of } \\
\text { the epiglottis }\end{array}$ & SL & moderate & $1 / 52$ & - \\
\hline 3 & 60 & Piriform sinus & TL & moderate & $6 / 21$ & + \\
\hline 4 & 63 & $\begin{array}{l}\text { Pharyngeal surface } \\
\text { of the epiglottis }+ \\
\text { base of the tongue }\end{array}$ & SL & moderate & $4 / 29$ & + \\
\hline 5 & 65 & $\mathrm{R}$ glottis + subglottis & TL & moderate & $3 / 64$ & $?$ \\
\hline 6 & 69 & R glottis + subglottis & TL & moderate & $1 / 13$ & - \\
\hline 7 & 59 & $\mathrm{R}$ piriform sinus & TL & moderate & $3 / 27$ & - \\
\hline 8 & 63 & $\begin{array}{l}\text { Supraglottis }+ \text { L vocal } \\
\quad \text { cord }\end{array}$ & $\mathrm{TL}$ & moderate & $4 / 24$ & + \\
\hline 9 & 52 & $\begin{array}{l}\text { L piriform sinus } \\
\quad+\text { base of the tongue }\end{array}$ & $\mathrm{TL}$ & poor & $9 / 46$ & + \\
\hline 10 & 40 & $\mathrm{R}$ piriform sinus & TL & moderate & $36 / 42$ & + \\
\hline 11 & 77 & $\mathrm{R}$ piriform sinus & TL & moderate & $2 / 30$ & + \\
\hline 12 & 67 & Glottis + subglottis & $\mathrm{TL}$ & moderate & $4 / 25$ & + \\
\hline 13 & 66 & $\mathrm{~L}$ piriform sinus & TL & well & $6 / 22$ & + \\
\hline 14 & 58 & $\mathrm{~L}$ piriform sinus & TL & moderate & $1 / 17$ & + \\
\hline 15 & 46 & $\mathrm{R}$ piriform sinus & TL & moderate & $2 / 39$ & + \\
\hline 16 & 47 & $\mathrm{R}$ vallecula & SL & moderate & $2 / 60$ & - \\
\hline 17 & 43 & $\mathrm{R}$ piriform sinus & TL & moderate & $3 / 36$ & - \\
\hline 18 & 64 & Epiglottis & SL & moderate & $9 / 32$ & - \\
\hline 19 & 61 & L glottis + subglottis & TL & well & $6 / 31$ & $?$ \\
\hline 20 & 66 & Epiglottis & $\mathrm{TL}$ & moderate & $4 / 42$ & - \\
\hline 21 & 60 & Supraglottis & SL & moderate & $1 / 27$ & + \\
\hline 22 & 49 & $\mathrm{R}$ piriform sinus & $\mathrm{TL}$ & moderate & $1 / 14$ & + \\
\hline 23 & 66 & R glottis & TL & moderate & $2 / 15$ & + \\
\hline 24 & 46 & Vallecula & SL & moderate & $5 / 51$ & + \\
\hline 25 & 69 & L piriform sinus & TL & moderate & $2 / 26$ & - \\
\hline 26 & 63 & Vallecula & TL & moderate & $9 / 13$ & + \\
\hline 27 & 76 & Supraglottis & SL & moderate & $3 / 23$ & - \\
\hline 28 & 74 & Supraglottis & SL & well & $2 / 19$ & + \\
\hline 29 & 67 & L glottis & TL & moderate & $4 / 23$ & $?$ \\
\hline 30 & 68 & Supraglottis & SL & moderate & $1 / 20$ & $?$ \\
\hline 31 & 57 & $\begin{array}{l}\text { Posterior pharyngeal } \\
\text { wall }\end{array}$ & Commando & well & $2 / 21$ & + \\
\hline 32 & 51 & $\mathrm{~L}$ piriform sinus & TL & poor & $4 / 12$ & - \\
\hline
\end{tabular}

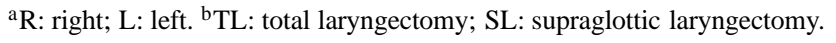

areas were then randomly selected from each tissue section and interactively delimited with the cursor of the image processing system, assessing that only tumour tissue was enclosed. The size of each area was approximately $0.07 \mathrm{~mm}^{2}$. Five immunostaining intensity measurements were generated from each section and marker; the mean of these data was then consid- ered as the average immunostaining intensity and this was a variable taken into account for statistical analyses. Coefficients of variation were calculated from these means and the standard deviations computed from each sample. When the immunostaining patterns were rather heterogeneous, as in the case of E-cadherin and TM, the percentage of immunostained cells was 
also determined as the relation between the numbers of stained and total pixels. In these two cases, a parameter defined as the mean of multiplying the immunostaining intensity by the percentage of stained cells within the five areas under evaluation was considered.

On the other hand, the distribution of intensities measured for each marker was divided into three intervals according to percentiles 33.3 and 66.6, and these were considered as low, intermediate and high immunostaining levels.

Statistical analyses were carried out using the SPSS 6.1.3 program. Relationships between pairs of markers were studied by using Spearman correlation coefficients. The means of paired data were compared by the Student's $t$-test.

\section{Results}

\subsection{Immunohistochemical features}

Antibody reactivity patterns on the normal pharynx/ larynx epithelium were the same as those previously described for squamous epithelium $[5,13,14]$. The former observed immunostaining intensities were taken as a reference and were always higher than those measured in primary tumours and metastases for any of the four molecules.

The immunostaining of E-cadherin was heterogeneous within the nests of the primary tumours. In well differentiated tumours, the staining was low in the less differentiated outer cells, and high in the more mature central layers. In the three poorly differentiated tumours analyzed, E-cadherin immunostaining was hardly visible.

In contrast to the aforementioned pattern of E-cadherin, CD44H and CD44v6 immunostaining was high and homogeneous in most of the outer cell layers of the tumoural nests, being lower or null in the central corneal pearls. The staining of these isoforms in the poorly differentiated samples fluctuated between low and intermediate levels.

The immunostaining characteristics of TM were intermediate between those previously described for E-cadherin and CD44. This immunostaining was heterogeneous among different tumoural nests and even within areas of the same nest. Central corneal pearls were either slightly negative or slightly positive. The most peripheral layer of tumoural nests was almost negative, reproducing the immunostaining pattern of the normal squamous epithelium whose basal layer is
Table 2

Immunostaining coefficients of variation (\%)

\begin{tabular}{lcc}
\hline & Tumour & Metastasis \\
\hline E-cadherin & 65.6 & 66.7 \\
TM & 41.8 & 54.5 \\
CD44H & 4.9 & 5.6 \\
CD44v6 & 4.6 & 5.1 \\
\hline
\end{tabular}

essentially TM negative. The three poorly differentiated samples were hardly immunostained with the antiTM antibody.

The patterns in lymph node metastases of the four molecules were similar to those observed in the corresponding primary tumours.

\subsection{Statistical analyses}

As shown in Table 2, the coefficients of variation were rather high for E-cadherin and TM, reflecting the aforementioned immunostaining heterogeneity.

Figure 1 shows the distribution into immunostaining levels of the four markers in the 64 samples analyzed. The percentages of cases which showed decreased, no change or increased immunostaining of lymph node metastases were: 31,50 and $19 \%$ for E-cadherin; 25, 63 and $12 \%$ for TM; 9,63 and $28 \%$ for CD44H; and 22, 53 and 25\% for CD44v6, respectively.

When subjected to Spearman's tests, correlations in the expression of these molecules were found only between CD44H and CD44v6, in both primary tumours and metastases $(r=0.65, p=0.000 ; r=0.54$, $p=0.003$, respectively), and between E-cadherin and TM in metastases $(r=0.59, p=0.003)$. By way of illustration, Fig. 2 reproduces the immunostaining patterns observed in case no. 6 .

Figure 3 shows the relative immunostaining intensity developed by the four antibodies in primary tumours and in their lymph node metastases. When the means of paired data were subjected to Student's $t$-tests, no significant differences were found in any of the four cases. In the case of E-cadherin and TM, if just the mean immunostaining intensities were considered (see Materials and methods), then $p$ values were 0.245 and 0.342 , respectively. This fact also reinforces the lack of significant quantitative differences in the immunostaining of these two molecules between the primary tumours and their lymph node metastases. 


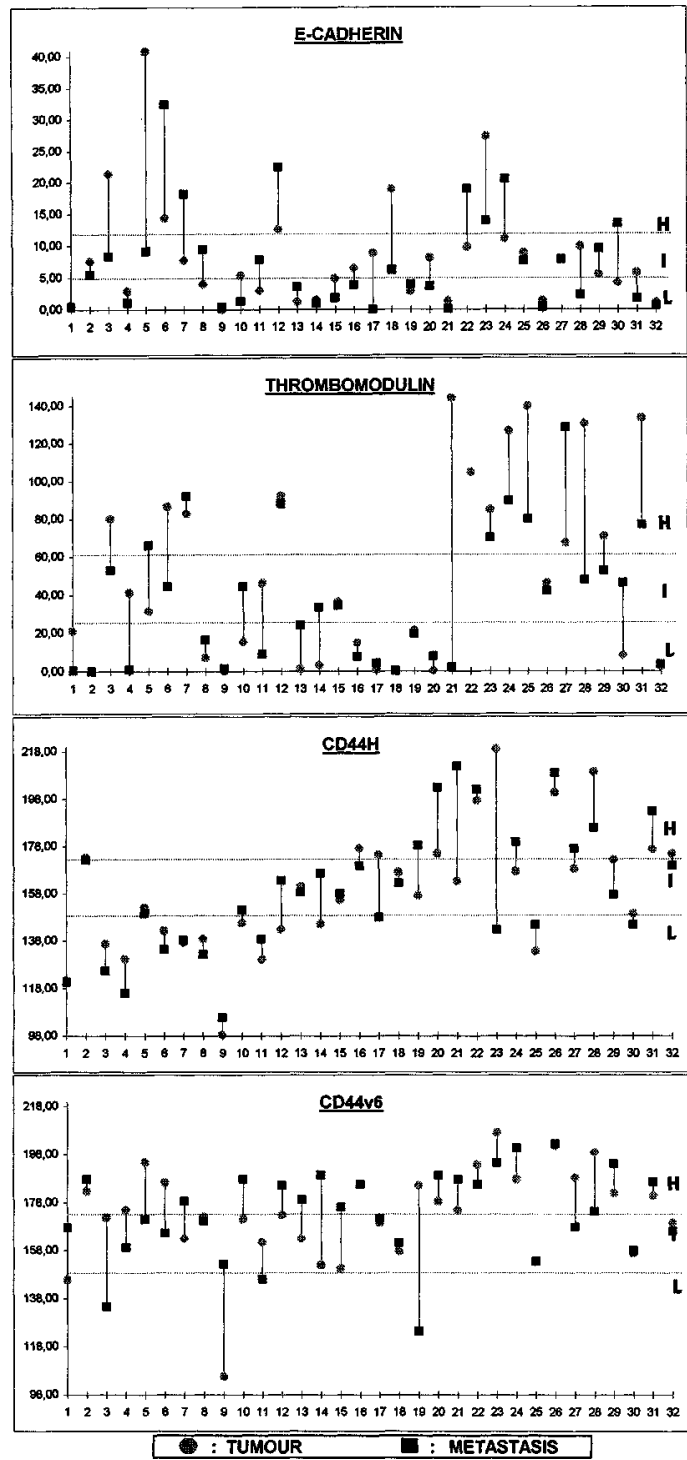

Fig. 1. Distribution into immunostaining levels. A particular immunostaining scale was set up for each marker; high $(\mathrm{H})$, intermediate (I) and low (L) inmunostaining levels were established as described in "Materials and methods".

\section{Discussion}

The relationships between the cell adhesion phenotype of primary and metastatic tumour cells in HNSCC have not been analyzed in detail.

Schipper et al. [19] observed a decreased expression of E-cadherin in five out of eight lymph node metastases of HNSCC when compared with their corresponding primary tumours; no differences were found in the other three cases studied. Similar results have been recently reported [2] after analyzing a series of
14 cases. However, other studies $[3,13,23]$, also performed on a rather limited series of specimens, did not find significant differences in E-cadherin expression between primary tumours and lymph node metastases.

Tezuka et al. [28] reported, for the first time, an inverse correlation of TM expression with lymph node metastasis in esophageal SCC. In 59 patients who had lymph node metastases, TM expression was decreased in $69 \%$ of the metastatic lesions, whereas the rest showed no apparent change. Nevertheless, a more recent study [26] reported a variable expression of TM in 36 lymph node metastases of oral SCC, those with no change in comparison with the primary tumour being predominant $(53 \%)$.

Since it was reported that a CD44 isoform containing the v6 variant conferred metastatic potential to rat carcinoma cells [6], a wealth of studies has been addressed to the analysis of this possibility regarding different human tumours; observational data have been controversial [8]. With reference to HNSCC, the reported results have also been rather disparate. Whereas Salmi et al. [18] observed a downexpression of CD44v6 in lymph node metastases, later studies [9, $11,15,24]$ have led to the conclusion that the expression of isoforms containing this splice variant is essentially unaltered or not correlated with the metastatic phenotype.

All the aforementioned immunostaining observations have been the result of subjective scorings. We would also like to stress that most of the heretofore reported studies, with the exception of those carried out by Spafford et al. [25] and Andrews et al. [2], have focused on the expression of single adhesion molecules. For the present report, by keeping unaltered image acquisition conditions and by applying an image processing system, we have made comparative and objective measurements in the expression of E-cadherin, TM, CD44H and CD44v6 between the primary tumours and the corresponding lymph node metastases in a series of 32 patients with SCC of pharynx/larynx. We detected high standard deviations and consequently high coefficients of variation for E-cadherin and TM immunostaining, which are mostly attributable to the inherent heterogeneity on the expression of these markers, both within and among samples; in contrast, CD44H and CD44v6 immunostaining was rather homogeneous. After statistical analysis, we have not found significant quantitative differences in the expression of any of these markers between the two tumour presentations. Thus, on the one hand and in accordance with previous reports $[3,9,11,13,15,23,24]$, it may be concluded from 


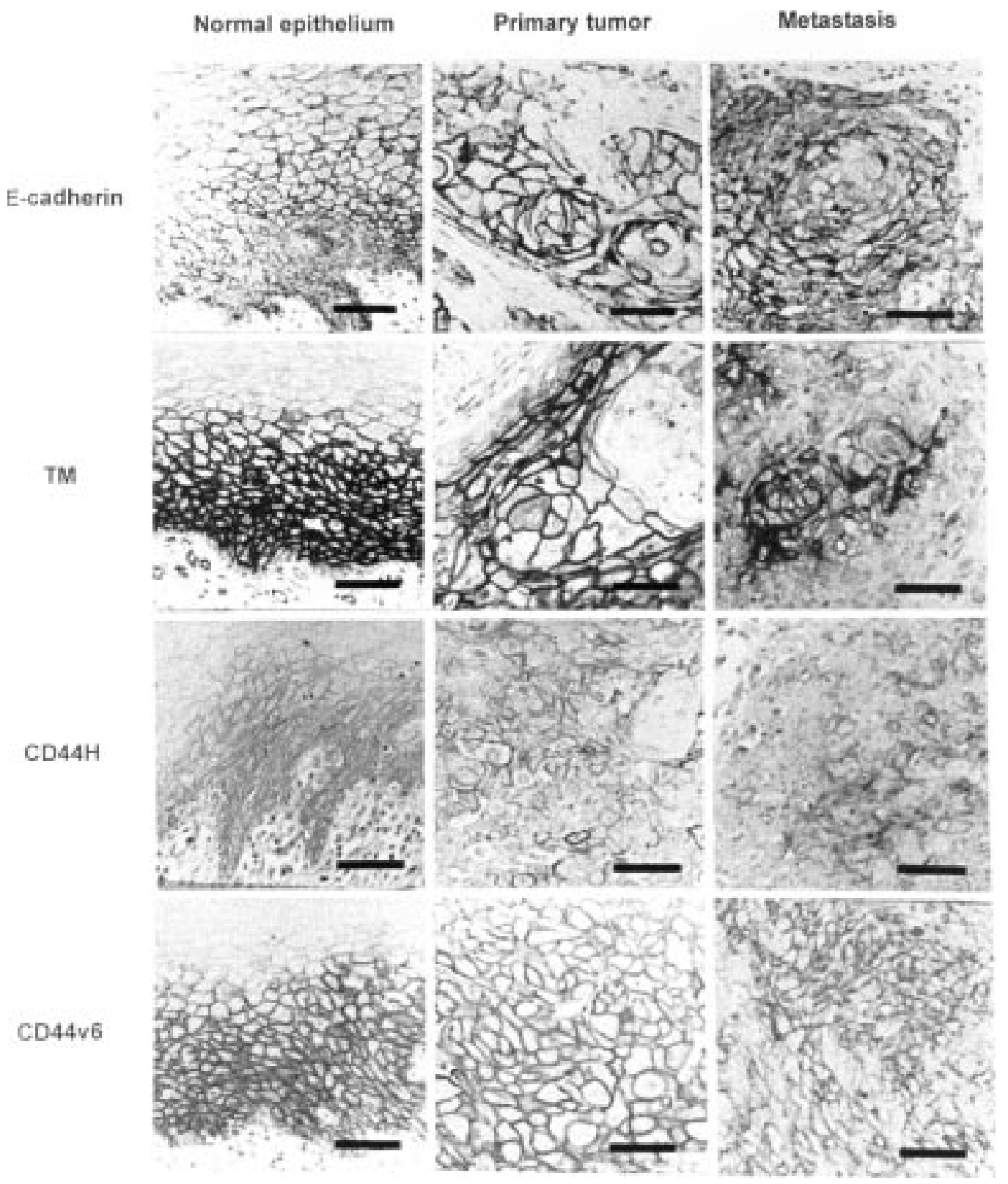

Fig. 2. Immunostaining patterns in case no. 6 . This was a moderately differentiated tumour with some discordant immunostaining levels between the two tumour sites. As shown in Fig. 1, these levels, in primary tumour and metastases, were respectively: high and high for E-cadherin; high and intermediate for TM; low and low for CD44H; and high and intermediate for CD44v6. Bars: $50 \mu \mathrm{m}$.

this study that the phenotype of established lymph node metastases in SCC of pharynx/larynx is not associated with quantitative changes in the expression of E-cadherin and CD44v6 in relation to the primary site.

On the other hand and to our knowledge, our work represents the first assessment of the expression of TM in lymph node metastasis of SCC of pharynx/larynx.
Our observations are at variance with those of Tezuka et al. [28] regarding lymph node metastases of SCC of the esophagus and are more in accordance with those of Tabata et al. [26] concerning SCC of the oral cavity, as we also found a majority (63\%) of metastases in which TM expression was similar to that measured in the corresponding primary tumour. Therefore, based on our observations, the metastatic phenotype of SCC 


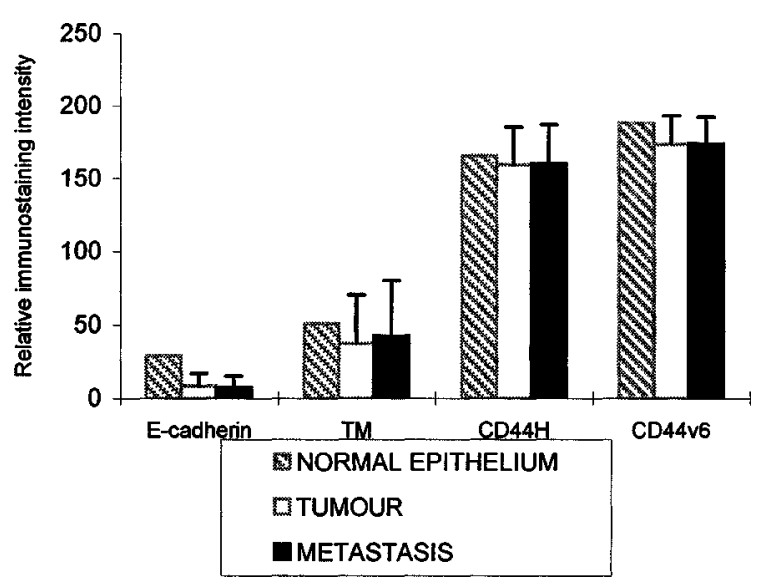

Fig. 3. Relative quantitative expression of the four markers in primary tumours and metastases. Histograms represent the mean immunostaining intensity of the 32 specimens analyzed; standard deviations are depicted as bars. Histograms regarding expression in normal pharynx/larynx epithelium refer to just one case (no. 6) and are included as a reference. The high standard deviations of E-cadherin and TM histograms, in comparison with those of CD44H and CD44v6, reflect the observed immunostaining heterogeneity of these markers.

of pharynx/larynx does not seem to be correlated with variations on the expression of TM either.

Conversely, while the positive expression of several other factors has been associated with the development of cancer metastases (for a comprehensive review, see [7]), the present study shows that this is not the case for E-cadherin, TM, CD44H or CD44v6 in HNSCC.

Along with their metastatic potential, the expression of these adhesion molecules has also been associated with the differentiation of epithelial cells $[2,12-15,19$, $21,23,24,26]$. In our series, regarding well and moderately differentiated tumours, the observed immunostaining intensities of the four markers could be ascribed to any of the three levels we have distinguished. In agreement with previous reports [2,3,19,20,23], E-cadherin expression was rather low or negative in the three poorly differentiated specimens we analyzed, as well as that of TM, but otherwise we measured intermediate expression levels of CD44H/CD44v6 in some of these samples. Altogether, we have not found significant correlations among the expression of the four markers, except in the case of CD44H and CD44v6, as expected [5,8,21,29], and between E-cadherin and TM in metastases.

Some of the previously reported observations and the ones described here seem to play down the role of the involved adhesion molecules in HNSCC lymph node metastasis. Nevertheless, we should be cautious as to the significance of these findings. On the one hand, all these studies have dealt with the starting (primary tumour) and the final stage (established metastases) of tumour progression but they have not considered the phenotype of tumour emboli on their way to the metastatic site. As has been argued for E-cadherin [13], the downexpression of surface adhesion molecules could facilitate the detachment of epithelial cells from the primary tumour mass; later on, after this transient phenotype associated with the migrant metastatic status, their normal expression could be regained and even upgraded during metastasis settlement and progression. In this context, it has been shown [17] that the microenvironment of different organs can profoundly influence the pattern of gene expression and consequently the phenotype of metastatic tumour cells. The particular microenvironment of the metastatized lymph node could explain the hereby observed correlated expression of E-cadherin and TM in this setting. On the other hand, the E-cadherin-catenin cell adhesion complex can be non-functional $[2,4,16]$ and, therefore, our quantitative E-cadherin immunoreactivity observations do not exclude the possibility of relevant qualitative differences in the function of this complex between the primary tumours and their lymph node metastases. All these considerations warrant further detailed analysis.

\section{Acknowledgements}

The authors are grateful to Carlos Gamallo, Departamento de Anatomía Patológica, Hospital La Paz, Madrid; to Angel Martínez-Nistal and to Enrique Fernández-Bustillo for their assistance with E-cadherin immunostaining, image processing and statistical analyses, respectively. R.H.G. was a recipient of a predoctoral fellowship from the Asociación Española contra el Cáncer. This work was supported by FlCYT, Principado de Asturias, Spain, Project PA-MAS96-01; part of it was presented at the 5th ESACP Congress in Oslo, May 25-29, 1997 and at the 11th International Congress on Diagnostic Quantitative Pathology, Siena, 2-4 October, 1997.

\section{References}

[1] S.M. Albelda, Role of cell adhesion molecules in tumor progression and metastasis, in: Adhesion Molecules, C.D. Wegner, ed., Academic Press, London, 1994, pp. 71-88. 
[2] N.A. Andrews, A.S. Jones, T.R. Helliwell and A.R. Kinsella, Expression of the E-cadherin-catenin cell adhesion complex in primary squamous cell carcinomas of the head and neck and their nodal metastases, Br. J. Cancer 75 (1997), 1474-1480.

[3] G.L. Bowie, A.W. Caslin, N.J. Roland, J.K.MA. Field, A.S. Jones and A.R. Kinsella, Expression of the cell-cell adhesion molecule E-cadherin in squamous cell carcinoma of the head and neck, Clin. Otolaryngol. 18 (1993), 196-201.

[4] M.E. Bracke, F.M. Van Roy and M.M. Mareel, The Ecadherin/catenin complex in invasion and metastasis, in: Attempts to Understand Metastasis Formation I, CTMI 213/I, U. Günthert and W. Birchmeier, eds, Springer-Verlag, Berlin, 1996, pp. 123-161.

[5] S.B. Fox, J. Fawcett, D.G. Jackson, I. Collins, K.C. Gatter, A.L. Harris, A. Gearing and D.L. Simmons, Normal human tissues, in addition to some tumors, express multiple different CD44 isoforms, Cancer Res. 54 (1994), 4539-4546.

[6] U. Günthert, M. Hofmann, W. Rudy, S. Reber, M. Zöller, I. Haussmann, S. Matzku, A. Wenzel, H. Ponta and P. Herrlich, A new variant of glycoprotein CD44 confers metastatic potential to rat carcinoma cells, Cell 65 (1991), 13-24.

[7] U. Günthert and W. Birchmeier, eds, Attempts to Understand Metastasis Formation I and II, CTMI 213/I and CTMI 213/II, Springer-Verlag, Berlin, 1996.

[8] U. Günthert, CD44 in malignant disorders, in: Attempts to Understand Metastasis Formation I, CTMI 213/I, U. Günthert and W. Birchmeier, eds, Springer-Verlag, Berlin, 1996, pp. 271285.

[9] C. Herold-Mende, S. Seiter, A.I. Born, E. Patzelt, M. Schupp, J. Zöller, F.X. Bosch and M. Zöller, Expression of CD44 splice variants in squamous epithelia and squamous cell carcinomas of the head and neck, J. Pathol. 179 (1996), 66-73.

[10] A.S. Jones, J.A. Cook, D.E. Phillips and N.R. Roland, Squamous carcinoma presenting as an enlarged cervical lymph node, Cancer 72 (1993), 1756-1761.

[11] M. Kunishi, Y. Kayada and K. Yoshiga, Down-regulated expression of CD44 variant 6 in oral squamous cell carcinomas and its relationship to regional lymph node metastasis, Int. J. Oral. Maxillofac. Surg. 26 (1997), 280-283.

[12] D.J. Lager, E.J. Callaghan, S.F. Worth, T.J. Raife and S.R. Lentz, Cellular localization of thrombomodulin in human epithelium and squamous malignancies, Am. J. Pathol. 146 (1995), 933-943.

[13] V. Mattijssen, H.M. Peters, L. Schalkwijk, J.J. Manni, B. Van't Hof-Grootenboer, P.H.M. De Mulder and D.J. Ruiter, Ecadherin expression in head and neck squamous-cell carcinoma is associated with clinical outcome, Int. J. Cancer 55 (1993), 580-585.

[14] H. Mizutani, T. Hayashi, N. Nouchi, S. Ohyanagi, K. Hashimoto, M. Shimizu and K. Suzuki, Functional and immunoreactive thrombomodulin expressed by keratinocytes, J. Invest. Dermatol. 103 (1994), 825-828.

[15] J. Piffkò, À. Bànkfalvi, K. Klauke, R. Dreier, U. Joos, W. Böcker and K.W. Schmid, Unaltered strong immunohistochemical expression of CD44-v6 and -v5 isoforms during development and progression of oral squamous cell carcinomas, J. Oral Pathol. Med. 25 (1996), 502-506.

[16] M. Pignatelli, Integrins, cadherins, and catenins: Molecular cross-talk in cancer cells, J. Pathol. 186 (1998), 1-2.
[17] R. Radinsky, Modulation of tumor cell gene expression and phenotype by the organ-specific metastatic environment, Cancer Metastasis Rev. 14 (1995), 323-338.

[18] M. Salmi, K. Grón-Virta, P. Sointu, R. Grenman, H. Kalimo and S. Jalkanen, Regulated expression of exon v6 containing isoforms of CD44 in man: downregulation during malignant transformation of tumors of squamocellular origin, J. Cell Biol. 122 (1993), 431-442.

[19] J.H. Schipper, U.H. Frixen, J. Behrens, A. Unger, K. Jahnke and W. Birchmeier, E-cadherin expression in squamous cell carcinomas of the head and neck: inverse correlation with tumor dedifferentiation and lymph node metastasis, Cancer Res. 51 (1991), 6328-6337.

[20] J.H. Schipper, A. Unger and K. Jahnke, E-cadherin as a functional marker of the differentiation and invasiveness of squamous cell carcinoma of the head and neck, Clin. Otolaryngol. 19 (1994), 381-384

[21] L. Sherman, J. Sleeman, P. Dall, A. Hekele, J. Moll, H. Ponta and P. Herrlich, The CD44 proteins in embryonic development and in cancer, in: Attempts to Understand Metastasis Formation I, CTMI 213/I, U. Günthert and W. Birchmeier, eds, Springer-Verlag, Berlin, 1996, pp. 249-269.

[22] G.B. Snow, A.A. Annyas, E.A. van Slooten, H. Bartelink and A.A.M. Hart, Prognostic factors of neck node metastasis, Clin. Otolaryngol. 7 (1982), 185-192.

[23] S.M. Sorscher, V. Russack, M. Cagle, J.R. Feramisco and M.R. Green, Immunolocalization of E-cadherin in human head and neck cancer, Arch. Pathol. Lab. Med. 119 (1995), 82-84.

[24] T. Soukka, M. Salmi, H. Joensuu, L. Häkkinen, P. Sointu, L. Koulu, K. Kalimo, P. Klemi, R. Grénman and S. Jalkanen, Regulation of CD44v6- containing isoforms during proliferation of normal and malignant epithelial cells, Cancer Res. 57 (1997), 2281-2289.

[25] M.F. Spafford, J. Koeppe, Z. Pan, P.G. Archer, A.D. Meyers and W.A. Franklin, Correlation of tumor markers p53, bcl-2, CD34, CD44H, CD44v6, and Ki-67 with survival and metastasis in laryngeal squamous cell carcinoma, Arch. Otolaryngol. Head Neck Surg. 122 (1996), 627-632.

[26] M. Tabata, K. Sugihara, S. Yonezawa, S. Yamashita and I. Maruyama, An immunohistochemical study of thrombomodulin in oral squamous cell carcinoma and its association with invasive and metastatic potential, J. Oral Pathol. Med. 26 (1997), 258-264.

[27] A. Tamura, O. Matsubara, K. Hirokawa and N. Aoki, Detection of thrombomodulin in human lung cancer cells, Am. J. Pathol. 142 (1993), 79-85.

[28] Y. Tezuka, S. Yonezawa, I. Maruyama,Y. Matsushita, T. Shimizu, H. Obama, M. Sagara, K. Shirao, C. Kusano, S. Natsugoe, H. Yoshinaka, M. Baba, T. Fukumoto, T. Aikou and E. Sato, Expression of thrombomodulin in esophageal squamous cell carcinoma and its relationship to lymph node metastasis, Cancer Res. 55 (1995), 4196-4200.

[29] M. Zöller, Joint features of metastasis formation and lymphocyte maturation and activation, in: Attempts to Understand Metastasis Formation I, CTMI 213/I, U. Günthert and W. Birchmeier, eds, Springer-Verlag, Berlin, 1996, pp. 215247. 


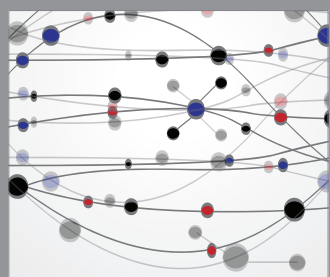

The Scientific World Journal
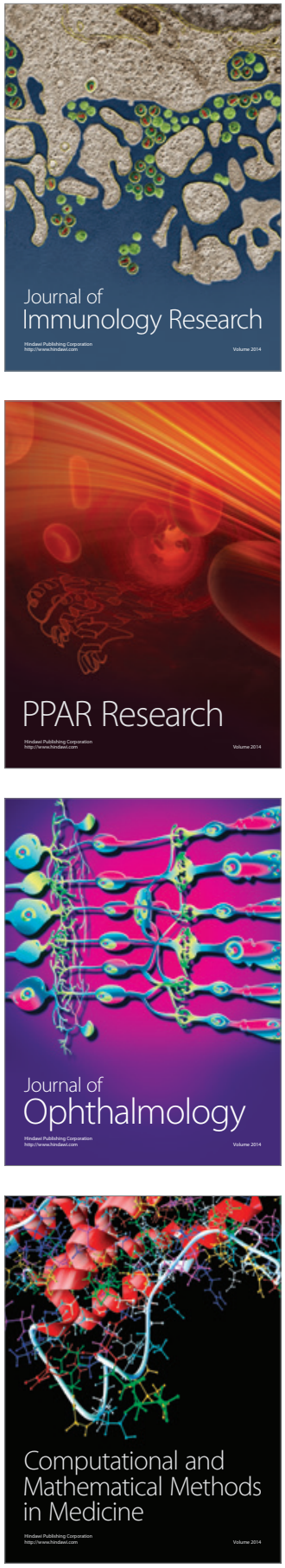

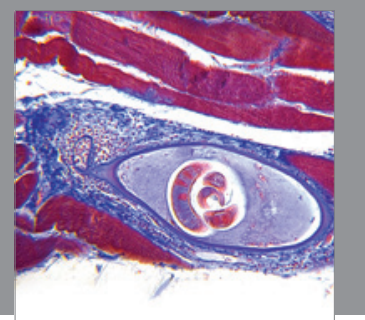

Gastroenterology

Research and Practice
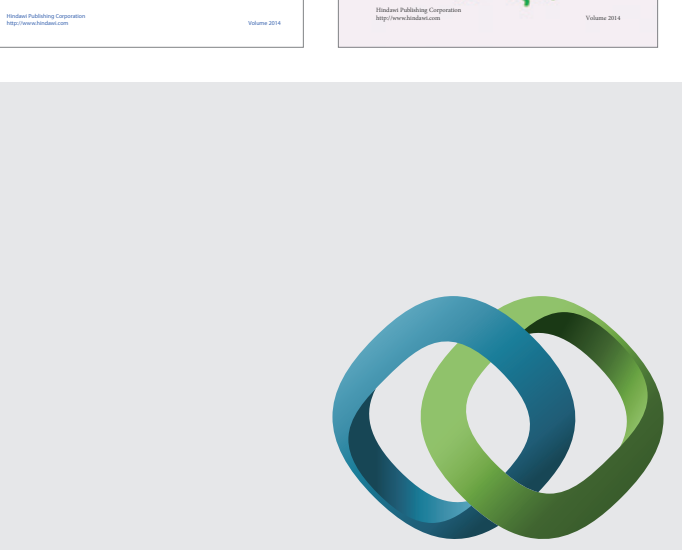

\section{Hindawi}

Submit your manuscripts at

http://www.hindawi.com
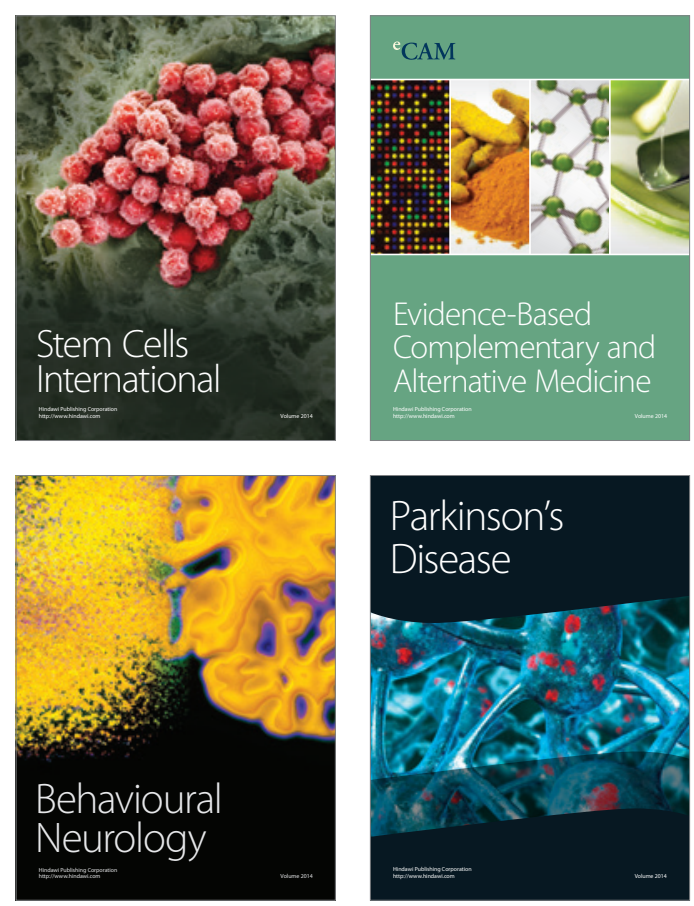

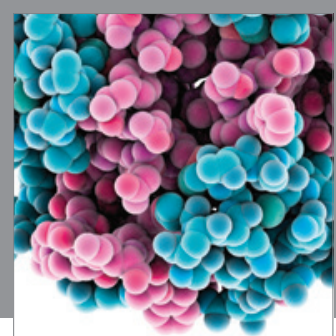

Journal of
Diabetes Research

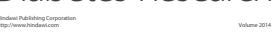

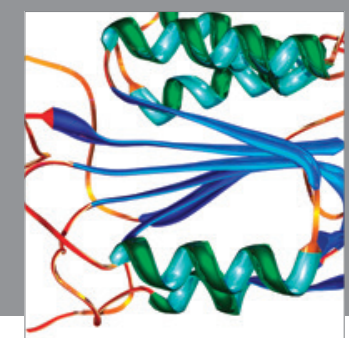

Disease Markers
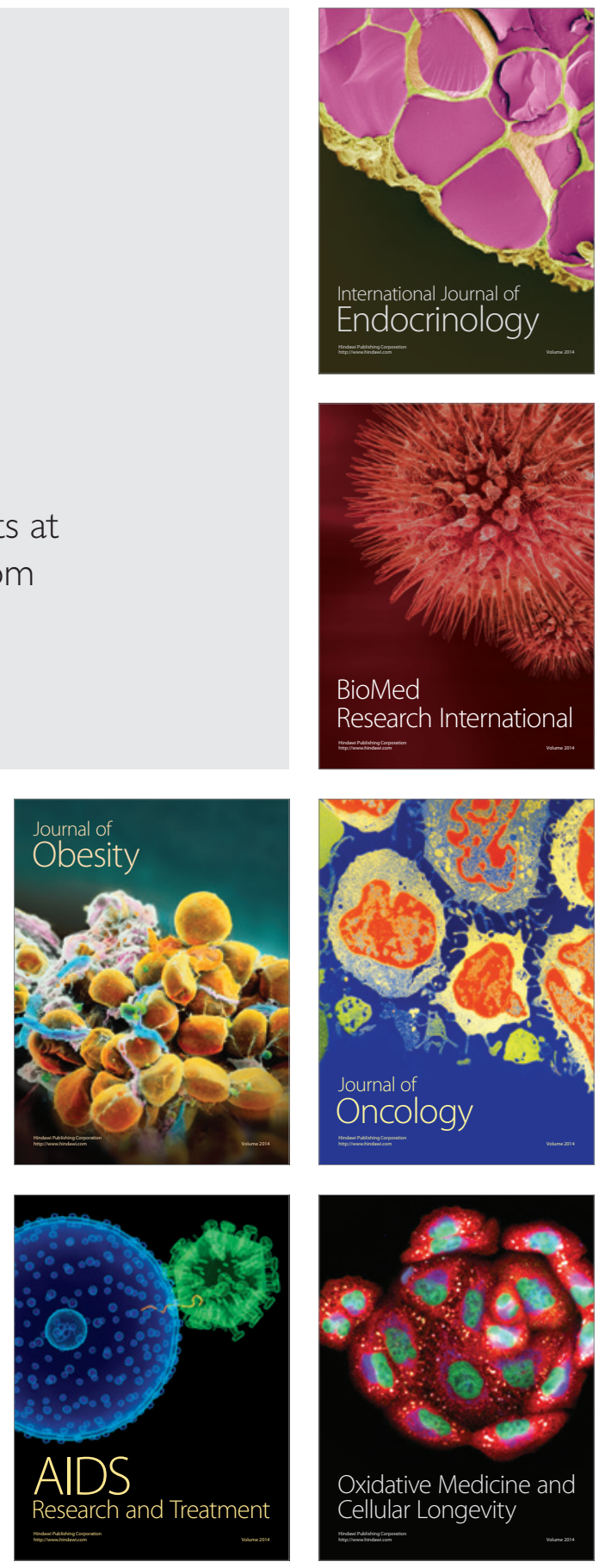